\title{
The use of dermoscopy following a one-day workshop among family medicine residnets
}

\author{
Dylan Maldonado, BS', Kathleen M. O'Hanlon, MD'1
}

ABSTRACT

Skin cancer is the most common form of cancer in the United States. The purpose of this study is to determine if a single grand rounds workshop impacts the use of dermoscopy in a family medicine residency training program. Dermoscopy is a non-invasive tool to allow for higher magnification of skin lesions thereby increasing the ability to assess qualities which are unable to be seen by the naked eye. This study utilized a pre- and post-workshop survey questionnaire to assess participant practices in evaluation, diagnosis, and management of skin lesions. Eighteen residents completed the survey prior to the grand rounds workshop. Nine residents completed the follow-up survey three-months post-workshop. The results showed that the frequency of dermoscopy use increased post-workshop (Pearson's Chi Square $=8.83, p=0.012$; Fischer's Exact $=0.008$ ) and residents felt dermoscopy decreased the need to refer skin lesions (Pearson's Chi Square=9.11, $p=0.028$; Fischer's Exact=0.023). However, there was no significant change in resident comfort level when using dermoscopy post-educational workshop (Pearson's Chi Square $=5.34, \mathrm{p}=0.255$; Fischer's Exact=0.272).
Author affiliations are listed at the end of this article.

Correspondence to:

Dylan Maldonado, BS Marshall University Joan C. Edwards School of Medicine maldonado7@marshall.edu

\section{KEYWORDS}

Dermoscopy, melanoma, family medicine, skin cancer, magnification, diagnose

\section{INTRODUCTION}

Skin cancer is the most common form of cancer in the United States. ' Among the types of skin cancers, melanoma is the leading cause of skin cancer deaths. ${ }^{1,2}$ Individuals who die as a result of melanoma average 20.4 years of potential life lost versus 16.6 years of potential life lost with other malignant cancers. ${ }^{2}$ Early detection is crucial in the prognosis of melanoma skin cancer. The 5 -year-survival rate if detected early and if less than $1 \mathrm{~mm}$ in thickness is greater than $94 \%$ versus a survival rate of less than $56.6 \%$ once the lesion is over $4 \mathrm{~mm} .^{3-5}$ Primary care physicians are often the first evaluators of skin cancers and thus play a crucial role in the detection of skin cancers. Dermoscopy is a non-invasive tool that allows for higher magnification of skin lesions and gives providers the ability to assess qualities of lesions that cannot be seen by the naked eye. ${ }^{6}$
Utilizing dermoscopy when evaluating skin lesions has been shown to improve the ability of primary care physicians and medical students to detect skin cancers. $^{7,8}$

The goal of this study was to determine if a single informative grand rounds workshop focusing on the use of dermoscopy would impact the practices of family medicine residents. The authors hypothesized that after the workshop, the residents would increase their use of dermoscopy in clinical practice and also have an increased level of comfort when evaluating skin lesions with dermoscopy.

\section{METHODS}

This study received IRB approval. An anonymous seven question survey (Appendix 1) was administered 
to residents in the Department of Family and Community Health at Marshall University Joan C. Edwards School of Medicine in Huntington, WV. The survey utilized a Likert scale to determine the participant's current practices in evaluation, diagnosis, and management of skin lesions. Initially, eighteen residents were surveyed $(n=18)$. The participants attended a ninety-minute grand rounds workshop that discussed the instrumentation involved in dermoscopy, the benefits of its use, and how to use dermoscopy when evaluating skin lesions.

Three months after the workshop the survey was re-administered via an online form to participating residents to see if their practices had changed to any degree. Nine residents completed the survey at three months following the workshop $(n=9)$. The survey was administered again at six-months post-workshop; however, only three participants responded. Due to a low response rate, the data from the six-months postworkshop survey has been excluded.

\section{RESULTS}

Eighteen residents completed the survey prior to the grand rounds workshop. Nine residents completed the follow-up survey after three months. The responses to these surveys can be found in Table 1 below. This study focused on the responses to questions 5, 6 and 7, which refer to the utilization of dermoscopy. Charts showing the percentage of residents who responded to each answer choice at pre-workshop and post-workshop are plotted below (Figures 1-3).

Question number five of the survey looked at how frequently residents used dermoscopy when evaluating skin lesions. The Chi-square test for association showed that at the 95\% Confidence Interval, there was a significant change in the frequency of dermoscopy utilization by residents post-educational workshop (Pearson's Chi Square $=8.83, \mathrm{p}=0.012$; Fischer's Exact $=0.008$ ). Question number six assessed comfort levels when using dermoscopy. The Chi-square test for association showed that at the $95 \%$ Confidence Interval, there was no significant change in resident comfort level when using dermoscopy post- educational workshop (Pearson's Chi Square $=5.34$, $p=0.255$; Fischer's Exact $=0.272$ ). Question number seven assessed whether residents felt dermoscopy decreased their need to refer skin lesions. The Chisquare test for association showed that at the $95 \%$ Confidence Interval, utilizing dermoscopy decreases the need for referral of some skin lesions evaluated by residents (Pearson's Chi Square $=9.11, p=0.028$; Fischer's Exact $=0.023$ ).

\section{STATISTICS}

The data were analyzed using STATA.

A Chi-Square Test for Association with a Fischer Exact Test was performed for each question on the survey questionnaire. The results of the statistical analysis are as follows in Table 2.

\section{DISCUSSION}

Skin conditions are one of the most common reasons for health care visits. In a study performed by the Mayo Clinic in a population in Minnesota, $42.7 \%$ of the patients had at least one ICD-9 code for a skin condition in a 5-year period, the most frequent type of any condition. ${ }^{9}$ Many individuals with skin conditions or lesions are not seen on a regular basis by a dermatologist. In fact, primary care providers are often the ones who are first evaluating suspicious skin lesions and sometimes the only physicians a patient may consult for skin care. ${ }^{10}$ This reiterates the importance for the need of primary care physicians to accurately and confidently diagnose and refer suspicious skin lesions when needed.

Dermoscopy allows providers to thoroughly visualize qualities of skin lesions in a non-invasive manner. Numerous studies have shown that dermoscopy provides primary care providers with an advantage when viewing pigmented skins lesions and increases diagnostic abilities compared to the naked eye.6,11-14 Dermoscopy has been shown to increase sensitivity for melanoma detection without a change in specificity among family physicians. ${ }^{11,14}$ The use of dermoscopy has also been shown to increase the 


\begin{tabular}{|c|c|c|c|}
\hline Survey Question & $\begin{array}{l}\text { Response } \\
\text { Options }\end{array}$ & $\begin{array}{l}\text { Response prior to } \\
\text { workshop }(\mathrm{n}=18) \\
\text { (number, \%) }\end{array}$ & $\begin{array}{c}\text { Response } 3 \text { months } \\
\text { post-workshop }(n=9) \\
\text { (number, \%) }\end{array}$ \\
\hline \multirow{4}{*}{$\begin{array}{l}\text { 1. I routinely ask patients if } \\
\text { they have any changing or } \\
\text { growing moles. }\end{array}$} & Never & $7,39 \%$ & $0,0 \%$ \\
\hline & Sometimes & $9,50 \%$ & $8,89 \%$ \\
\hline & Frequently & $1,6 \%$ & $1,11 \%$ \\
\hline & Always & $1,6 \%$ & $0,0 \%$ \\
\hline \multirow{4}{*}{$\begin{array}{l}\text { 2. I routinely include a } \\
\text { skin evaluation in my } \\
\text { physical exams. }\end{array}$} & Never & $0,0 \%$ & $0,0 \%$ \\
\hline & Sometimes & $15,83 \%$ & $6,67 \%$ \\
\hline & Frequently & $2,11 \%$ & $2,22 \%$ \\
\hline & Always & $1,6 \%$ & $1,11 \%$ \\
\hline \multirow{5}{*}{$\begin{array}{l}\text { 3. I am comfortable making } \\
\text { the diagnosis of seborrheic } \\
\text { keratosis. }\end{array}$} & $\begin{array}{l}\text { Strongly } \\
\text { Disagree }\end{array}$ & $0,0 \%$ & $0,0 \%$ \\
\hline & Disagree & $0,0 \%$ & $0,0 \%$ \\
\hline & Neutral & $3,17 \%$ & $2,22 \%$ \\
\hline & Agree & $10,55 \%$ & $3,33 \%$ \\
\hline & Strongly Agree & $5,28 \%$ & $4,44 \%$ \\
\hline \multirow{5}{*}{$\begin{array}{l}\text { 4. I am comfortable with } \\
\text { my ability to recommend a } \\
\text { skin lesion needs biopsy. }\end{array}$} & $\begin{array}{l}\text { Strongly } \\
\text { disagree }\end{array}$ & $0,0 \%$ & $0,0 \%$ \\
\hline & Disagree & $2,11 \%$ & $0,0 \%$ \\
\hline & Neutral & $6,33 \%$ & $3,33 \%$ \\
\hline & Agree & $8,44 \%$ & $4,44 \%$ \\
\hline & Strongly Agree & $2,11 \%$ & $2,22 \%$ \\
\hline \multirow{4}{*}{$\begin{array}{l}\text { 5. I use dermoscopy when } \\
\text { evaluating skin lesions. }\end{array}$} & Never & $17,94 \%$ & $4,44 \%$ \\
\hline & Sometimes & $1,6 \%$ & $4,44 \%$ \\
\hline & Frequently & $0,0 \%$ & $1,11 \%$ \\
\hline & Always & $0,0 \%$ & $0,0 \%$ \\
\hline \multirow{5}{*}{$\begin{array}{l}\text { 6. I am comfortable } \\
\text { assessing skin lesions with } \\
\text { the dermoscope. }\end{array}$} & $\begin{array}{l}\text { Strongly } \\
\text { disagree }\end{array}$ & $8,44 \%$ & $2,22 \%$ \\
\hline & Disagree & $5,28 \%$ & $1,11 \%$ \\
\hline & Neutral & $4,22 \%$ & $3,34 \%$ \\
\hline & Agree & $0,0 \%$ & $1,11 \%$ \\
\hline & Strongly Agree & $1,6 \%$ & $2,22 \%$ \\
\hline \multirow{5}{*}{$\begin{array}{l}\text { 7. Dermoscopy use } \\
\text { decreases my need to refer } \\
\text { some skin lesions. }\end{array}$} & $\begin{array}{l}\text { Strongly } \\
\text { disagree }\end{array}$ & $1,6 \%$ & $2,22 \%$ \\
\hline & Disagree & $4,23 \%$ & $0,0 \%$ \\
\hline & Neutral & $11,65 \%$ & $3,33 \%$ \\
\hline & Agree & $1,6 \%$ & $4,44 \%$ \\
\hline & Strongly Agree & $0,0 \%$ & $0,0 \%$ \\
\hline
\end{tabular}

TABLE 1. Responses to initial survey and three-months post-education workshop.

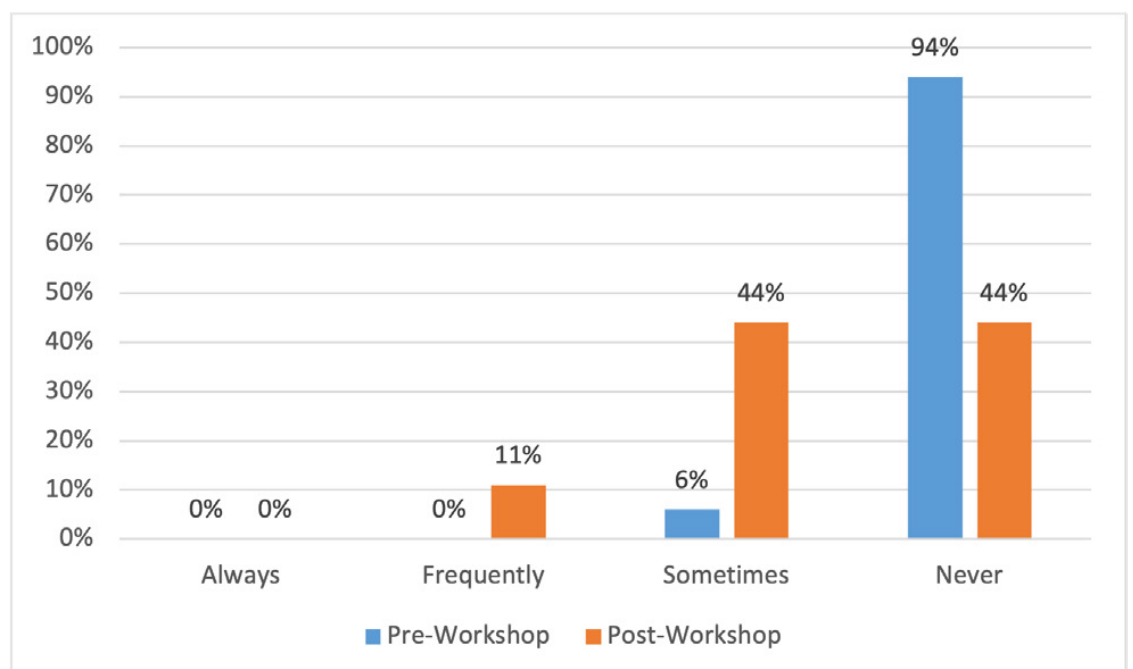

FIGURE 1. Chart showing the resident responses to question 5 on the pre- and post-workshop survey.

Marshall Journal of Medicine

Volume 5 Issue 1 


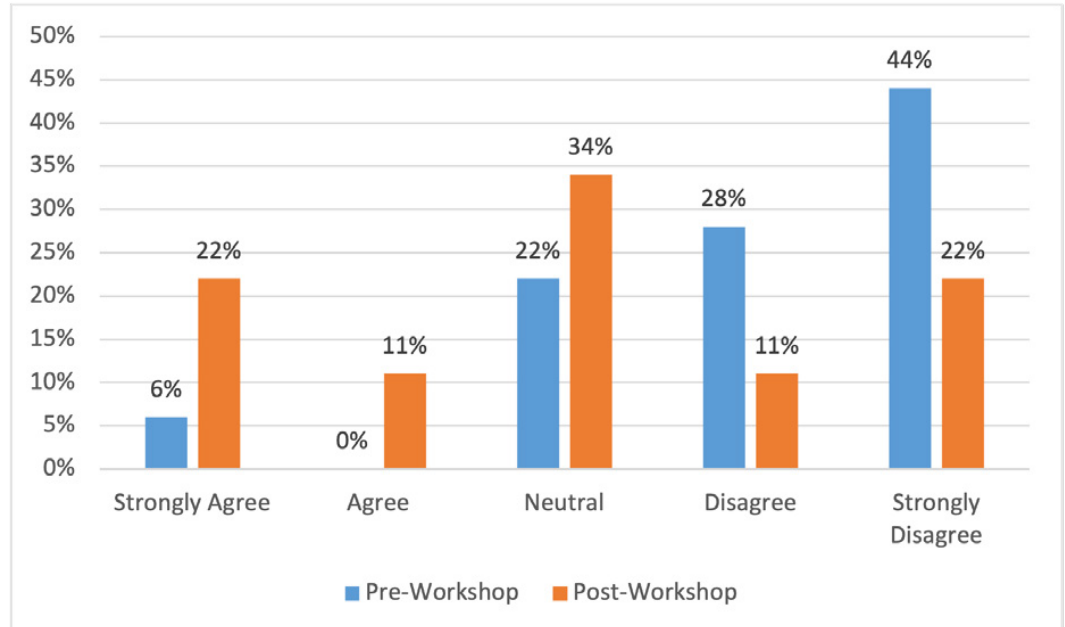

FIGURE 2. Chart showing the resident responses to question 6 on the pre- and post-workshop survey.

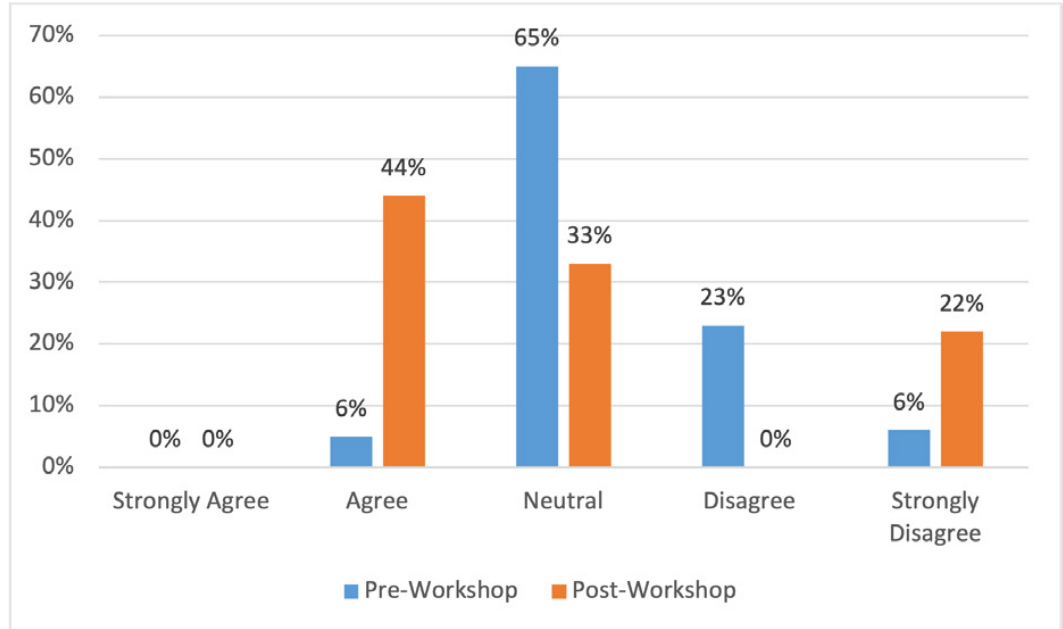

FIGURE 3. Chart showing the resident responses to question 7 on the pre- and post-workshop survey.

confidence of primary care providers when deciding when to refer suspicious lesions for biopsy or further evaluation. ${ }^{11,14}$

Increasing diagnostic accuracy of primary care providers in relation to dermatologic skin conditions should theoretically lead to an increase in the detection of melanoma and non-melanoma skin cancers. This is important because early detection of melanoma skin cancers has a major impact on survival. Melanoma that is detected early, at a lower stage, has a higher five and ten-year survival. A T1aNOM0 melanoma has a 5 -year survival of $93 \%$ versus a T4aNOM0 melanoma having a 53\% five-year survival rate. ${ }^{5}$
Short training sessions utilizing dermoscopy, such as the one-time workshop in this study, have been shown to be effective in leading to an increase in diagnostic accuracy of melanoma and nonmelanoma skin cancers among physicians following these short day-or-less training courses. ${ }^{15,16}$ Our study aimed to build on this principle and show that a single grand rounds dermoscopy workshop can also lead to an increase in the use of dermoscopy among residents at three months and improve triage capabilities of residents.

The results of this study indicate that a single grand rounds workshop has the potential to increase the use of dermoscopy among family medicine residents and have an effect on the decision to refer 


\begin{tabular}{|c|c|c|c|}
\hline $\begin{array}{c}\text { Question } \\
\text { Number }\end{array}$ & $\begin{array}{c}\text { Pearson's Chi } \\
\text { Squared Value }\end{array}$ & p-value (95\% CI) & Fischer's Exact \\
\hline 1 & 5.69 & 0.128 & 0.079 \\
\hline 2 & 0.96 & 0.617 & 0.479 \\
\hline 3 & 1.22 & 0.545 & 0.562 \\
\hline 4 & 1.50 & 0.682 & 0.872 \\
\hline 5 & 8.83 & 0.012 & 0.008 \\
\hline 6 & 5.34 & 0.255 & 0.272 \\
\hline 7 & 9.11 & 0.028 & 0.023 \\
\hline
\end{tabular}

Table 2. Results of Chi-Square Test of Association for each question on the survey questionnaire. Questions 5 and 7 showed statistically significant results.

skin lesions. Our study did not show a significant change in resident comfort levels post-workshop. However, we would expect that resident comfort levels would increase with repeated training and more frequent utilization of dermoscopy in practice. The importance of primary care providers being adequately trained to diagnose and refer skin lesions has been discussed in this paper. The use of dermoscopy can bridge the gap between primary care providers and dermatologists through the recognition and diagnoses of skin cancers to allow for earlier treatment in the critical periods.

\section{CONCLUSION}

Dermoscopy has been shown to be a valuable tool in the diagnosis and evaluation of skin lesions. This study indicates that a single grand rounds workshop has the ability to impact the use of dermoscopy among family medicine residents. The results of this study demonstrated a statistically significant increase in the frequency of use of dermoscopy among residents and a statistically significant decrease in their need to refer skin lesions following a single dermoscopy workshop. However, a single educational workshop did not lead to a statistically significant increase in comfort levels when utilizing dermoscopy. Even though the results of the study indicate that a single workshop can be successful in impacting the behaviors of family medicine residents, further research is needed to provide more evidence.

\section{LIMITATIONS}

This study was limited by the number of residents who responded to the survey at three and sixmonths following the workshop. The study was also limited by the diversity of the residents as all of the residents surveyed were from a single residency program at a single institution. Data analysis was limited by the survey being administered as anonymous which prevents the data from being analyzed as a paired sample. The study could be improved upon by having a larger sample size and with a more diverse group of participants. Future studies should attempt to attain a higher response rate and follow residents longitudinally for longer than three months to investigate whether a single workshop could induce sustained behavioral changes. Future studies could also actually monitor the frequency in which residents utilize dermoscopy and refer skin lesions prior to and following the workshop intervention to determine changes in behavior.

\section{ACKNOWLEDGMENTS}

The project was supported by the Marshall University School of Medicine Appalachian Clinical and Translational Science Institute (ACTSI). The content is solely the responsibility of the authors and does not necessarily represent the official views of the ACTSI. 


\section{AUTHOR AFFILIATIONS}

1. Marshall University Joan C. Edwards School of Medicine, Huntington, West Virginia

\section{REFERENCES}

1. Guy GP Jr, Thomas CC, Thompson T, et al. Vital signs: melanoma incidence and mortality trends and projections-United States, 1982-2030. MMWR Morb Mortal Wkly Rep. 2015;64(21):591596.

2. Ekwueme DU, Guy GP Jr, Li C, et al. The health burden and economic costs of cutaneous melanoma mortality by race/ethnicity-United States, 2000 to 2006. Journal of the American Academy of Dermatology. 2011;65(5):S133-143.

3. Rigel DS., et al. ABCDE-an evolving concept in the early detection of melanoma. Archives of dermatology. 2005;141(8):1032-1034.

4. Pollack LA, Li J, Berkkowitz Z, et al. Melanoma survival in the United States, 1992 to 2005. Journal of the American Academy of Dermatology. 2011;65(5):S78-86.

5. Balch, Charles M., et al. Final version of 2009 AJCC melanoma staging and classification. Journal of clinical oncology. 2009;27(36):6199-6206.

6. 6. Vestergaard ME, Macaskill P, Holt PE, Menzies SW. Dermoscopy compared with naked eye examination for the diagnosis of primary melanoma: a meta-analysis of studies performed in a clinical setting. British Journal of Dermatology. 2008;159(3):669-676.

7. Herschorn A. Dermoscopy for melanoma detection in family practice. Canadian Family Physician. 2012;58(7):740-745.

8. Liebman TN, Goulart JM, Soriano R, et al. Effect of dermoscopy education on the ability of medical students to detect skin cancer. Archives of dermatology. 2012;148(9):1016-1022.

9. St. Sauver JL. St, Warner DO, Yawn BP, et al. Why patients visit their doctors: assessing the most prevalent conditions in a defined American population. Mayo Clinic Proceedings. 2013;88(1):56-67.

10. Verhoeven EWM, Kraaimaat FW, van Weel C, et al. Skin diseases in family medicine: prevalence and health care use. The Annals of Family Medicine. 2008;6(4):349-354.
11. Herschorn A. Dermoscopy for melanoma detection in family practice. Canadian Family Physician. 2012;58(7):740-745.

12. Argenziano G, Puig S, Zalaudek I, et al. Dermoscopy improves accuracy of primary care physicians to triage lesions suggestive of skin cancer. Journal of Clinical Oncology. 2006;24(12):1877-1882.

13. Westerhoff K, McCarthy WH, Menzies SW. Increase in the sensitivity for melanoma diagnosis by primary care physicians using skin surface microscopy. British Journal of Dermatology. 2000;143(5):1016-1020.

14. Menzies SW, Emery J, Staples M, et al. Impact of dermoscopy and short-term sequential digital dermoscopy imaging for the management of pigmented lesions in primary care: a sequential intervention trial. British Journal of Dermatology. 2009;161(6):1270-1277.

15. Chevolet I, Hoorens I, Janssens A, et al. A short dermoscopy training increases diagnostic performance in both inexperienced and experienced dermatologists. Australasian Journal of Dermatology. 2015;56(1):52-55.

16. Secker LJ, Bus PA, Bergman W, Kukutsch NA. Effect of a dermoscopy training course on the accuracy of primary care physicians in diagnosing pigmented lesions. Acta dermatovenereologica. 2017;97(2):263-265. 


\begin{tabular}{|c|c|c|}
\hline & $\begin{array}{l}\text { I routinely ask patients if they have } \\
\text { any changing or growing moles }\end{array}$ & $\begin{array}{ll} & \text { Never } \\
\circ & \text { Sometimes } \\
\circ & \text { Frequently } \\
\circ & \text { Always }\end{array}$ \\
\hline 2) & $\begin{array}{l}\text { I routinely include a skin evaluation in } \\
\text { my physical exams. }\end{array}$ & $\begin{array}{ll} & \text { Never } \\
\circ & \text { Sometimes } \\
\circ & \text { Frequently } \\
\circ & \text { Always }\end{array}$ \\
\hline 3) & $\begin{array}{l}\text { I am comfortable making the } \\
\text { diagnosis of seborrheic keratosis. }\end{array}$ & $\begin{array}{ll} & \text { Strongly Disagree } \\
\circ & \text { Disagree } \\
\circ & \text { Neutral } \\
\circ & \text { Agree } \\
\circ & \text { Strongly Agree }\end{array}$ \\
\hline 4) & $\begin{array}{l}\text { I am comfortable with my ability to } \\
\text { recommend a skin lesion needs } \\
\text { biopsy. }\end{array}$ & $\begin{array}{ll} & \text { Strongly disagree } \\
\circ & \text { Disagree } \\
\circ & \text { Neutral } \\
\circ & \text { Agree } \\
\circ & \text { Strongly Agree } \\
\end{array}$ \\
\hline 5) & $\begin{array}{l}\text { I use dermoscopy when evaluating } \\
\text { skin lesions. }\end{array}$ & $\begin{array}{ll}\circ & \text { Never } \\
\circ & \text { Sometimes } \\
\circ & \text { Frequently } \\
\circ & \text { Always } \\
\end{array}$ \\
\hline 6) & $\begin{array}{l}\text { I am comfortable assessing skin } \\
\text { lesions with the dermoscope. }\end{array}$ & $\begin{array}{ll}\circ & \text { Strongly disagree } \\
\circ & \text { Disagree } \\
\circ & \text { Neutral } \\
\circ & \text { Agree } \\
\circ & \text { Strongly Agree } \\
\end{array}$ \\
\hline 7) & $\begin{array}{l}\text { Dermoscopy use decreases my need to } \\
\text { refer some skin lesions. }\end{array}$ & $\begin{array}{ll} & \text { Strongly disagree } \\
\circ & \text { Disagree } \\
\circ & \text { Neutral } \\
\circ & \text { Agree } \\
\circ & \text { Strongly Agree } \\
\end{array}$ \\
\hline
\end{tabular}

APPENDIX 1. Survey questionnaire conducted prior to the educational workshop and three months post-workshop. 